Tohoku J. Exp. Med., 2003, 199, 119-126

Case Report

\title{
Pulmonary Lymphangioleiomyomatosis: A Case Report with Immunohistochemical Details and DNA Analysis
}

\author{
Li-Hua Pan, Harumasa Ito, ${ }^{1}$ Akira Kurose, Kohei Yamaguchi, ${ }^{1}$ HiROSHI \\ INOUE $^{1}$ and TAKASHI SAWAI \\ The First Department of Pathology, and ${ }^{1}$ The Third Department of Internal \\ Medicine, Iwate Medical University School of Medicine, Morioka 020-8505
}

Pan, L.-H., Ito, H., Kurose, A., Yamaguchi, K., Inoue, H. and Sawai, T. Pulmonary Lymphangioleiomyomatosis: A Case Report with Immunohistochemial Details and DNA Analysis. Tohoku J. Exp. Med., 2003, 199(2), 119-126-A 47-year-old woman is presented with pulmonary lymphangioleiomyomatosis (PLAM) involving the bilateral lung and slight pulmonary function abnormality. Computed tomography scan showed bilateral microcyst formation in the lung. Histologically, proliferating spindle shaped cells with centrilobular emphysema were main findings. Immunohistochemically, these proliferating spindle shaped cells were positive for $\alpha$-smooth muscle actin, desmin, vimentin, HMB45, estrogen receptor and progesterone receptor, but negative for S-100, cytokeratin. Single strand conformation polymorphism (SSCP) and DNA analysis for tuberous sclerosis 1 and 2 showed no significant abnormality._pulmonary lymphangioleiomyomatosis; HMB45

(C) 2003 Tohoku University Medical Press

Pulmonary lymphangioleiomyomatosis (PLAM) is a rare disease that occurs almost exclusively in women of reproductive age (Bonetti et al. 1993). It is manifested by HMB45 positive smooth muscle proliferation into peribronchial, perivascular, and other thoracic lymphatics, without any inflammatory cells or organized fibrosis (Bonetti et al. 1993; Itami et al. 1997). Usually it also shows centrilobular emphysema with decreased alveolar lung volume and internal surface area (Urban et al. 1992; Buckley and Deluca 1995; Tawfik et al. 1996;
Kimura et al. 1997; Yano 2002). Because of the overlap between PLAM and tuberous sclerosis (TSC), many observers believe that PLAM is an incomplete expression of TSC (Brentani et al. 1984; Capron et al. 1984). Clinical observations suggest that steroid hormones play an influential role in the biological behavior of PLAM, as the patients are women, and usually in their reproductive years. Brentani et al. (1984) reported that estrogen, progestin and glucocorticoid levels were significantly elevated in the patients with PLAM (Tawfik et al. 1996),

Received January 31, 2003; revision accepted for publication February 21, 2003.

Address for reprints: Takashi Sawai, M.D., Ph.D., The First Department of Pathology, Iwate Medical

University School of Medicine, Uchimaru 19-1, Morioka 020-8505, Japan.

e-mail: tsawai@iwate-med.ac.jp 
and dramatic clinical improvements in the subjective and objective respiratory function parameters were obtained by prescribing a regimen combining an anti-estrogenic agent and a progestin (Denoo et al. 1999; Yano 2002).

TSC is an autosomal dominant disorder in which patients develop hamartomatous lesions in many differentiated organs including lung. In precious study, most cases were sporadic and assumed to result from new mutations. Two TSC-determining loci have been mapped to chromosomes 9q34 (TSC1) and to 16p13 (TSC2). The TSC2 gene with 41 coding exons and TSC gene were identified in 1993 and in 1997 separately (The European Chromosome 16 Tuberous Sclerosis Consortium 1993; van Slegtenhorst et al. 1997).

Here we report a case of PLAM that may contribute to the knowledge on this disease.

\section{Clinical summary}

In April 1998, a 47-year-old Japanese woman, was introduced to Iwate Medical University, Third Department of Internal Medicine after her operation for a spontaneous pneumothorax. The left pneumothorax occurred on January 26, 1998. At that time her chest radiograph showed a bulla in the apex of the left lung and emphysema around it. The CT scan showed a $1-2 \mathrm{~cm}$ bulla and microcysts scattered in both lungs (Fig. 1). There was pleural thickening in the left major fissure. No significant interstitial pattern was shown in the either lung. She did not smoke. When she visited the clinical room, her temperature was $36.4^{\circ} \mathrm{C}$, the pulse was 75 , respiration was 20 , and blood pressure was 110/80. Cardiovascular system was unremarkable. Physical examination revealed no abnormal findings but coarse and fine cracks on the bilateral upper and lower back and spoon nail finger. Laboratory tests were performed on April 17, 1998. Both number and fraction of leukocytes were within the normal range but $\mathrm{Hb}, \mathrm{Ht}, \mathrm{MCV}$, and $\mathrm{MCH}$ showed lower levels. Neither ESR nor CRP increased. No abnormality in the biochemical examination was observed (data not shown). The data of pulmonary function test are presented with slight abnormality. There was no clinical evidence of mental retardation, angiofibroma or angiomyolipoma in the kidney or ovary.

Recently we had an opportunity to study a patient given a diagnosis of pulmonary lymphangiomyomatosis. The patient was a 47-year-old Japanese female with slowly progressive dyspnea, a cough and spontaneous pneumothoraces clinically. No other organ abnormality was observed. In lung tissues of the patient, smooth muscle proliferation into peribronchial, perivascular, and other thoracic

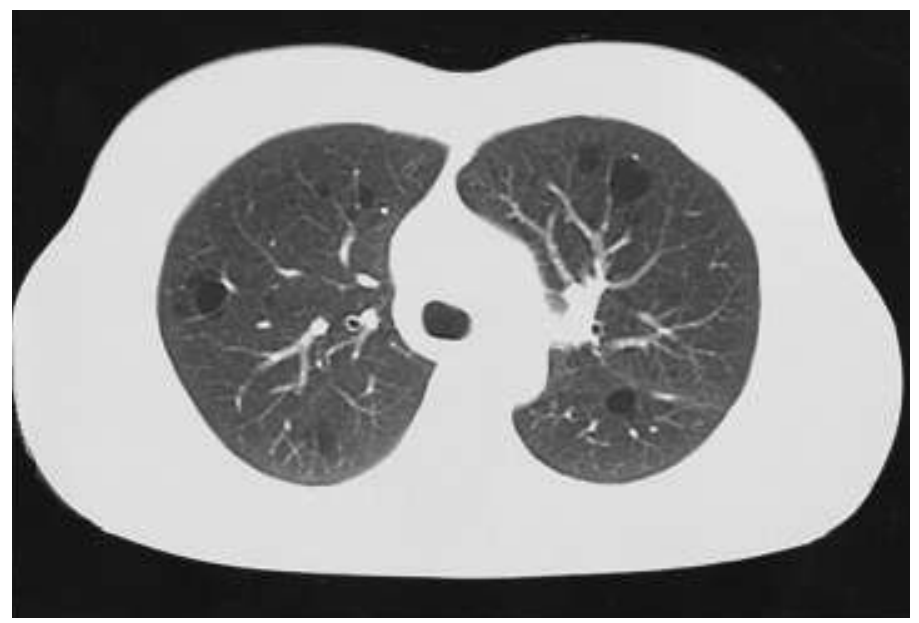

Fig. 1. CT scan showing microcyst formation in both sides of the lung. 
lymphatics were main findings. The proliferating smooth muscle was positive for HMB45 which is a specific marker of melanoma, and positive for a-smooth muscle actin ( $\alpha$-SMA), HHF-35, vimentin and desmin, progesterone receptor and estrogen receptor, but negative for S-100, cytokeratin.

\section{MATERIALS AND METHODS}

\section{Immunohistochemical staining}

Specimens obtained at open biopsy on April 24, 1998 were fixed in 4\% buffered formalin, and paraffin-embedded, after deparaffinization the sections were processed as an ordinary histological study, i.e., hematoxylin and eosin, elatica-Masson's trichrome staining, and additional immunohistochemical investigation of the lung was performed according to a standard protocol. Using the biotinylated streptavidin system, a Histofine Kit (Nichirei, Tokyo) was used. Deparaffinized sections were treated with $0.3 \%$ hydrogen peroxide in methanol for 15 minutes to block endogenous peroxidase activity. The sections were then incubated with the following primary antibody: $\alpha$-smooth muscle actin (Dako, Carpinter, CA, USA), desmin (Nichirei, Tokyo), vimentin (Nichirei, Tokyo), HHF-35 (Enzo Diagnostics, Farmingdale, NY, USA), Factor VIII (Nichirei, Tokyo), progesterone receptor (Novocastra, Newcastle, UK), estrogen receptor (Dako, Glostrup, Denmark), S-100 (Nichirei, Tokyo), cytokeratin (Nichirei, Tokyo) overnight at $4^{\circ} \mathrm{C}$. 3'3-diaminobenzidine (DAB) was used as the chromogenic substrate.

\section{Single-strand conformational polymorphism} analysis of genomic DNA

After getting the patient's informed consent to participate genomic study, genomic DNA was phenol-extracted from the patient's peripheral blood leukocytes and isolated by SDS/ proteinase $\mathrm{K}$ method. The single-strand conformational polymorphism (SSCP) analysis of genomic DNA was performed according to Yamashita's protocol (Yamashita et al. 2000).
Intronic primers of TSC1 were from Jones et al. (1997), except exons 5, 9,13 and 23. Another series of intronic primers were designed to achieve amplification throughout the coding region of TSC2 and exons 5, 9, 13 and 23 of TSC1. Polymerase chain reaction (PCR) was performed on genomic DNA with the intronbased primers flanking each of the exons. Each $10 \mu$ l PCR reaction mixture contained 50 ng of genomic DNA, $1 \mu$ l of $10 \times$ PCR buffer, 250 $\mu \mathrm{M}$ of each dNTP, $0.5 \mu \mathrm{M}$ of each primer, and I unite of Taq polymerase (Taq 101, Toyobo, Tokyo). Amplification was conducted for 35 cycles at $94^{\circ} \mathrm{C}$ for 30 seconds, at $54-60^{\circ} \mathrm{C}$ for 30 seconds, and at $72^{\circ} \mathrm{C}$ for 30 seconds in a thermal cycler (QTPI, Nippon Genetics, Tokyo). After PCR, $10 \mu 1$ of the PCR products was diluted with $100 \mu 1$ loading buffer, and $2 \mu 1$ aliquots were denatured at $95^{\circ} \mathrm{C}$ for 5 minutes, cooled on ice, and loaded on polyacrylamide gels. Electrophoresis was carried out with a sequencing-gel apparatus at $1200 \mathrm{~V}$ for $4-5$ hours. We examined several conditions of SSCP $(5,6$ or $8 \%$ polyacrylamide containing 10 or $0 \%$ glycerol at room temperature or at $4{ }^{\circ} \mathrm{C}$ for electrophoresis) and chose the best conditions for this study $(6 \%$ polyacrylamide gels with or without glycerol at $4^{\circ} \mathrm{C}$ ). After electrophoresis the gels were dried and exposed to $\mathrm{x}$-ray films at $-70^{\circ} \mathrm{C}$ overnight.

\section{$D N A$ sequencing and analysis}

PCR products that revealed shift bands on SSCP analysis were cut from the gels and recovered in $100 \mu 1 \mathrm{H}_{2} \mathrm{O}$ at $37^{\circ} \mathrm{C}$ overnight. Using the same primer, $20 \mathrm{ng}$ of recovered PCR products were amplified by the same PCR cycles. The resultant products were purified on agarose gels and DNA sequenced in sequencing buffer (310 Genetic Analyzer Buffer) with a DNA Sequence Kit for PRISM 310 Autosequencer (\#402079, Applied Biosystems), according to the manufacturer's protocol. PCR was performed as for the SSCP analysis without the $(\alpha$ - 
a

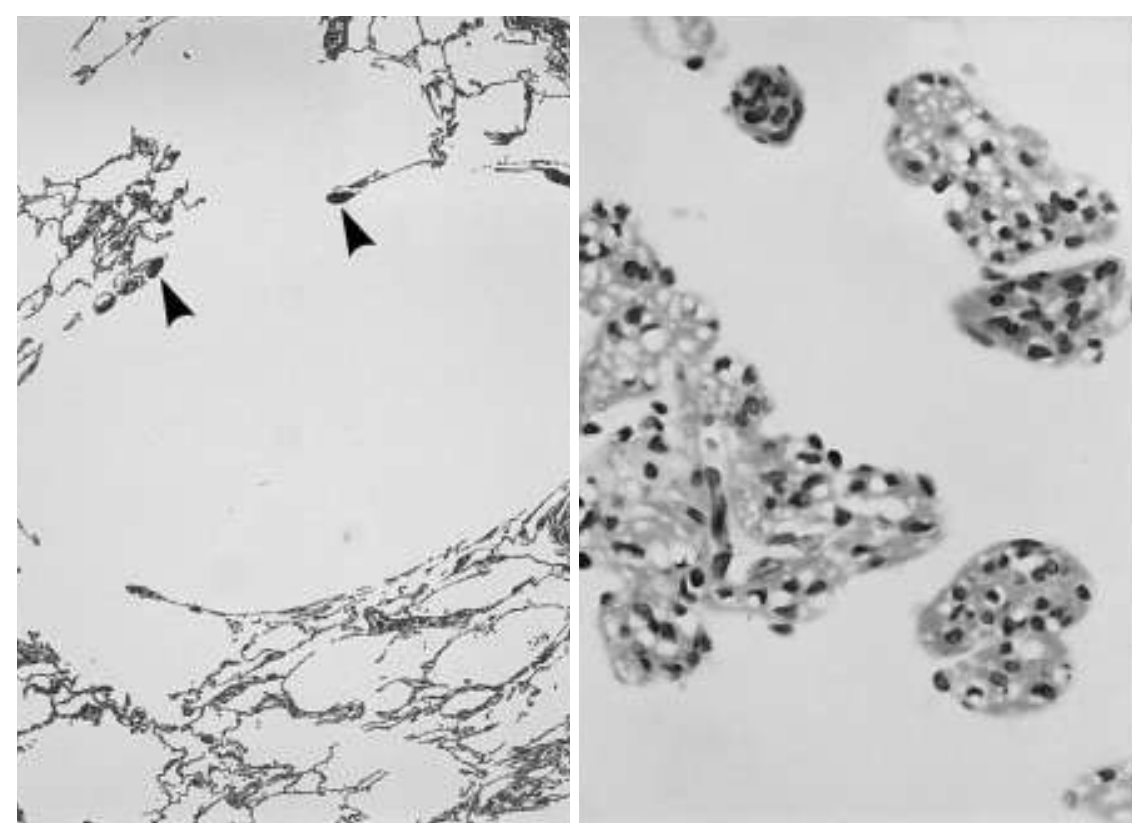

Fig. 2. Hematoxylin and eosin stain.

a: Variable sized emphysematous changes are seen throughout the bilateral lungs with knots (arrows) around the lymph and/or blood vessels in peripheral air away. In the surround the enlarged air space neither severe inflammation nor tumor are found $(\times 40)$. b: Spindle and oval cells (LAM cells) densely proliferate in corresponding to the above knotting regions $(\times 400)$.

$\left.{ }^{32} \mathrm{P}\right) \mathrm{dCTP}$.

\section{Pathological and immunohistochemical findings}

The lung tissue of an open biopsy confirmed that there is a focal fibrous thickening in the pleura (data not shown). Hyperplastic smooth muscle with a spindle cell pattern was observed in the lung tissue adjacent to areas of emphysema. These spindle cells proliferate in lymphatics and around small blood vessels as well as respiratory bronchioles, which causes pulmonary collapse, promoting emphysema. The spindle cells also proliferate inside alveoli and alveolar ducts (Fig. 1). Consecutive serial sections were used for immunohistochemical staining. The proliferating spindle cells showed positive immunoreactivity with antibodies of $\alpha$-smooth muscle actin ( $\alpha$-SMA), HHF-35, desmin, vimentin, HMB45, progesterone receptor, and estrogen receptor (Figs. 3a-3f), but negative for S-100, cytokeratin and Factor
VIII (data not shown). Lymphangioleiomyomatosis (LAM) was diagnosed.

The result of DNA sequencing, SSCP and DNA analysis

In this study, no significant pathogenic mutations were demonstrated on the exons of TSC1 and TSC2. Even a mutation was observed, which led to serine changing to arginine on S829R of TSC1. It was possibly polymorphism.

\section{DISCUSSION}

LAM is a rare disease of unknown etiology that exclusively affects women. The patient is usually at childbearing age (Sakano et al. 1989). PLAM can occur as an isolated disorder or is probably an incomplete expression of TSC (Capron et al. 1983; Kimura et al. 1997; Smolarek et al. 1998; Pallisa et al. 2002). TSC is an autosomal dominant disorder characterized by seizures, mental retardation, and hamar- 
a

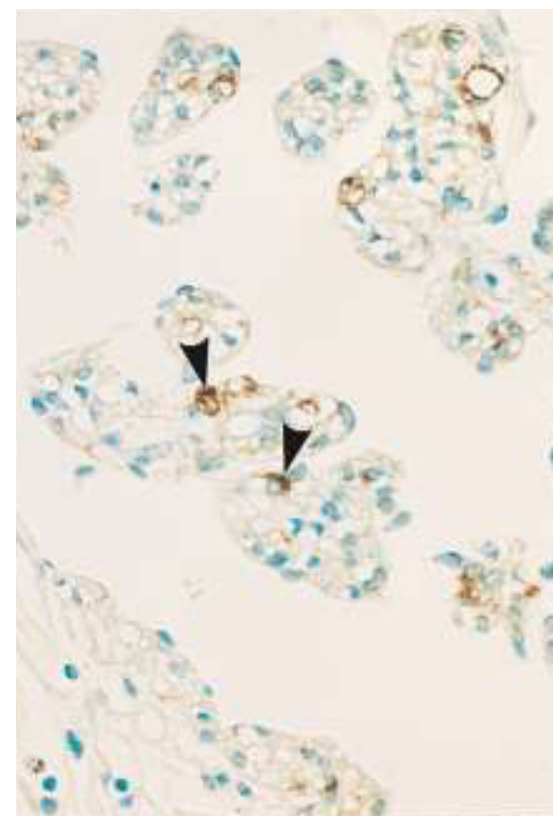

d

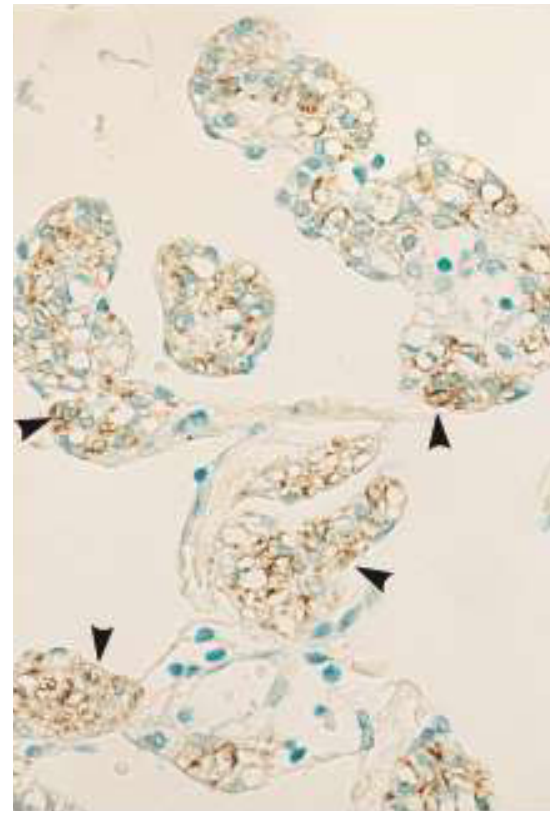

b

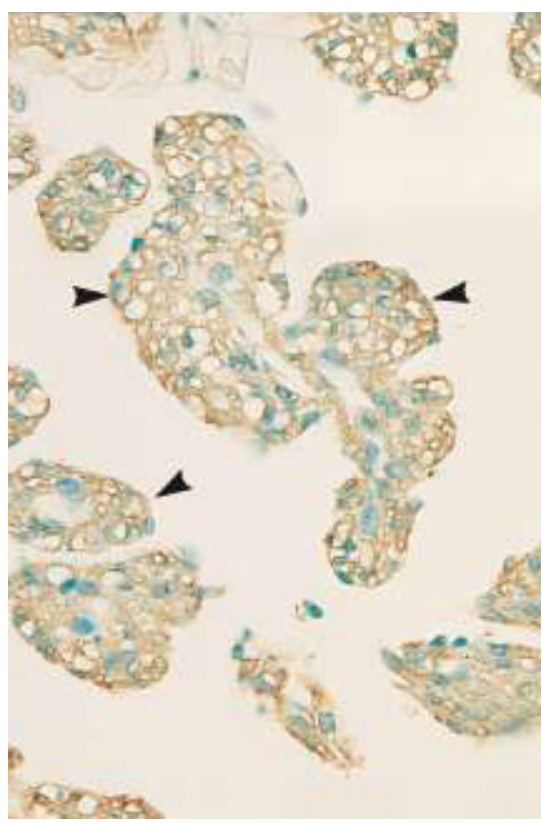

e
C

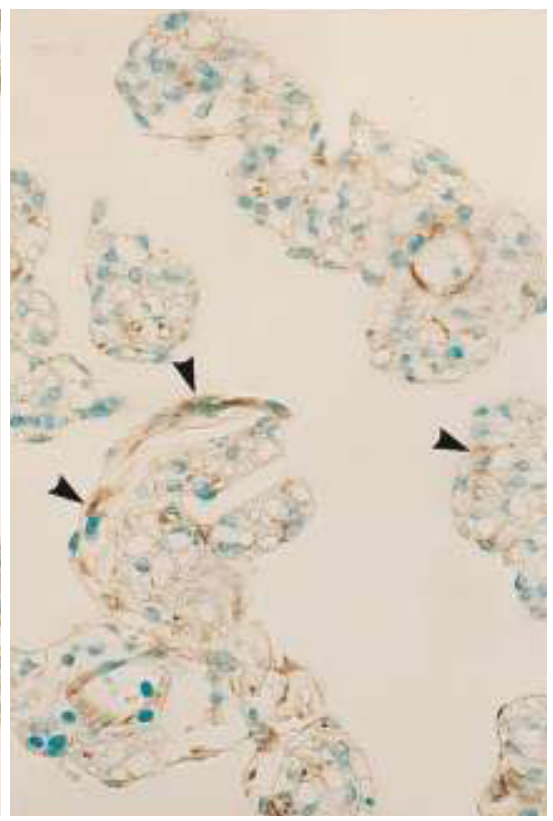

f

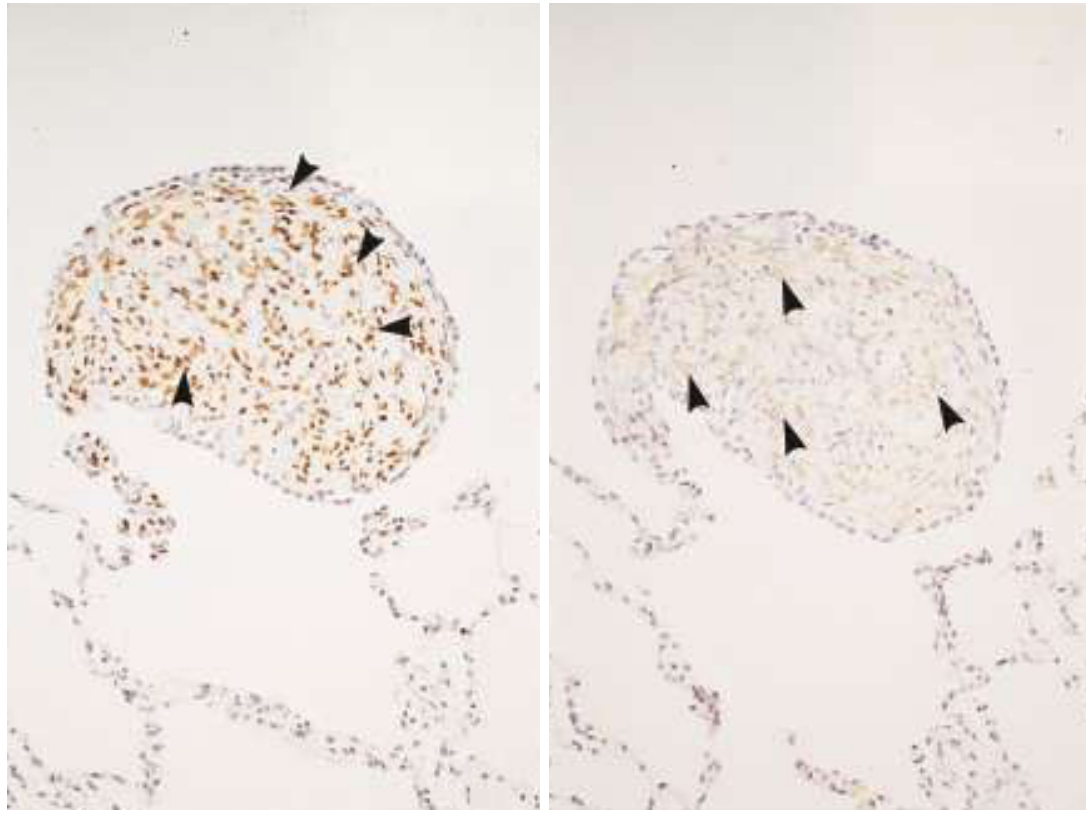

Fig. 3. Immunohistochemical staining to serial sections.

LAM cells are positive for HMB45(a), $\alpha$-SMA (b), Vimentin (c), Desimin (d), Progesterone receptor (e), and Estrogen receptor (f), demonstrated with brown color separately. All positive cells are indicated by arrows $(\times 400)$.

tomatous tumors of the brain, heart, kidney, lung, and skin. These tumors include cerebral cortical tubers, cardiac rhabdomyomas, renal angiomyolipomas, LAM, and facial angiofibromas (Capron et al. 1983; Kimura et al. 1997;
Smolarek et al. 1998). In the present case, no clinical evidence of tumor involving other organs, such as angiofibroma and angiolipoma, or other abnormalities were observed. The result of DNA sequencing, SSCP and DNA 
analysis for TSC1 and TSC2, showed no significant abnormality. This case was considered an isolated disorder, i.e., pulmonary lymphangioleiomyomatosis. Nevertheless, reactive muscle cell proliferation with chronic interstitial pneumonitis may be another possibility as differential diagnosis (Scully et al. 1994). However, except for emphysema and bulla almost no other abnormal finding was found in the lung in this case. Furthermore, native pulmonary muscular proliferation (NPMP) may also be another possibility as differential diagnosis (Wockel et al. 1997). PLAM is a progressive pulmonary disease in which pneumothorax is more frequently seen than in NPMP which is only a mild and temporary impairment of pulmonary function.

In previous reports, most patients (91\%) had abnormal pulmonary function tests. The most frequent abnormality was the decreased DLco found in $83 \%$ of the patients. This was followed by hypoxemia which was found in $57 \%$ of the patients (Chu et al. 1999). In our case, the pulmonary function test was slightly abnormal (Table 1), i.e., $\mathrm{PCO}_{2}, 48.1 \mathrm{mmHg}, \mathrm{PO}_{2}$, and $90.1 \mathrm{mmHg}$. This was likely due to a milder disease state, an early phase disease, or the cell proliferation involving only a small area. It is suggested that the flow limitation in LAM is caused more likely by the loss of alveolar support in the small airway than by excessive intramural smooth muscle proliferation. These smooth muscle cells proliferate in lymphatics and around small blood vessels as well as respiratory bronchioles, and cause their collapse, promoting emphysema. The time from onset of symptoms to death range from 1 . 3 to 27.5 years, with a mean of 8.5 years (Taylor et al. 1990).

HMB45 is a monoclonal antibody with high specificity against junctional nevi and malignant melanoma. Previous studies demonstrated proliferating smooth muscle cells of PLAM which had immunoreactivity with HMB45. Meanwhile, it is well-known that the normal,
TABle 1. Results of pulmonary-function test

\begin{tabular}{ll}
\hline $\mathrm{pH}$ & 7.372 \\
$\mathrm{PCO}_{2}$ & $48.1 \mathrm{mmHg}$ \\
$\mathrm{PO}_{2}$ & $90.1 \mathrm{mmHg}$ \\
Vital capacity (VC) & 2.76 liter \\
\%VC & $106 \%$ \\
Forced expiratory volume & \\
In one second (FEV1) & 2.52 liter \\
\%FEV1 & $91.3 \%$ \\
\hline
\end{tabular}

hyperplastic, and neoplastic smooth muscle in the lung is unreactive with HMB45 (Bonetti et al. 1993; Itami et al. 1997). This peculiar immunoreactivity helps in the differential diagnosis and suggests a distinctive role for smooth muscle cells in PALM. HMB45 is a much more important marker for the diagnosis of PLAM than desmin, vimentin, and $\alpha$ - SMA, since the latters are variably present in both PLAM cells and normal, hyperplastic, and neoplastic muscle cell. HMB45 can be used even for cytological examination to confirm the diagnosis (Bonetti et al. 1993; Itami et al. 1997).

Clinical observations suggest that steroid hormones play an influential role in the biological behavior of PLAM, as the patients are women, and usually in their reproductive ages (Brentani et al. 1984). Progesterone and estrogen receptors were investigated in our case and both showed positive immnuoreactivity in the proliferating smooth muscle cells. This finding provides evidence for association of progesterone and estrogen with PLAM.

In conclusion, as shown in this report, the smooth muscle cells in PLAM are phenotypically different from other smooth muscle cell proliferations. The diagnosis of PLAM by open biopsy can be improved by the availability of a marker, such as HMB45.

\section{Acknowledgments}

The authors wish to thank Prof. H. Sasano, Department of Pathology, Tohoku University, Sendai, Japan for performing PR and ER immuno- 
histochemical staining and valuable discussion; Dr. K. Seyama, Department of Respiratory Medicine, Juntendou Medical School, Tokyo, Japan for SSCP and DNA analyses and valuable discussion. The authors also appreciate Mr. Y. Shibata and Ms. M. Sasaki for their assistance in the experiments.

\section{References}

Bonetti, F., Chiodera, P.L., Pea, M., Martgnoni, G., Bosi, F., Zamaboni, G. \& Mariuzzi, G.M. (1993) Transbronchial biopsy in lymphangiomyomatosis of the lung for HMB45 for diagnosis. Am. J. Surg. Pathol., 17, 1092-1102.

Brentani, M.M., Carvalho, C.R.R., Saldiva, P.H., Pacheco, M.M. \& Oshima, C.T.F. (1984) Steriod receptors in pulmonary lymphangiomyomatosis. Chest, 85, 96-99.

Buckley, K.M. \& Deluca, S.A. (1995) Pulmonary lymphangiomyomatosis-radiographic highlights. American Family Physician, 51, 831 $-833$.

Capron, F., Ameille, J., Leclerc, P., Mornet, P., Barbagellata, M., Reynes, M. \& Rochemaure, J. (1983) Pulmonary lymphangiomyomatosis and Bournerville's tuberous sclerosis with pulmonary involvment: the same disease? Cancer, 52, 851-855.

Chu, S.C., Horiba, K., Usuki, J., Avila, N.A., Chen, C.C., Travis, W.D., Ferran, V.J. \& Moss, J. (1999) Comprehensive evaluation of 35 patients with lymphangioleiomyomatosis. Chest, 115, 1041-1052.

Denoo, X., Herman, G., Degive, R. \& Foidart, J.-M. (1999) Successful treatment of pulmonary lymphangioleiomyomatosis with progestin. Chest, 115, 276-279.

Itami, M., Teshima, S., Asakuma, Y., Chino, H., Aoyama, K. \& Fukushima, N. (1997) Pulmonary lymphangiomyomatosis diagnosed by effusion cytology. A case report. Acta Cytologica, 41, 522-528.

Jones, A.C., Daniells, C.E., Snell, R.G., Tachataki, M., Idziaszczyk, S.A., Krawczak, M., Sampson, J. R. \& Cheadle, J.P. (1997) Molecular genetic and phenotypic analysis reveals differences between TSC1 and TSC2 associated familial and sporadic tuberous sclerosis. Hum. Mol. Genet., 6, 2155-2161.

Kimura, N., Watanabe, M., Date, F., Kitamoto, T., Kimura, I., Akira, H. \& Nagura, H. (1997) HMB-45 and tuberin in hamartomas associat- ed with tuberous sclerosis. Mod. Pathol., 10, 952-959.

Pallisa, E., Sanz, P., Roman, A., Majo, J., Andreu, J. \& Caceres, J. (2002) Lymphangioleimyomatosis: pulmonary and abdominal findings with pathologic correlation. Radiographics, 22, S185-S198.

Sakano, T., Hamasaki, T., Kawaguschi, Y., Ueda, K. \& Hiramoto, T. (1989) Pulmonary lymphangiomyomatosis in childhood? Marked smooth muscle cell proleferation of the lung in a preadolescent girl with repeated pneumothorax and progressive dyspnea. Hiroshima J. Med. Sci., 38, 147-149.

Scully, R.E., Mark, E., McNeely, W. \& McNeely, B. U. (1994) Case records of the Massachusetts General Hospital, Pulmonary lymphangioleiomyomatosis. N. Engl. J. Med., 330, 1300-1306.

Smolarek, T.A., Wessner, L.L., McCormack, F.X., Mylet, J.C., Menon, A.G. \& Henske, E.P. (1998) Evidence that lymphangiomyomatoasis is caused by TSC2 mutations: chromosome $16 \mathrm{p} 13$ loss of heterozygosity in angiomyolipomas and lymph nodes from women with lymphangiomyomatosis. Am. J. Hum. Genet., 62, 810-815.

Tawfik, O., Austenfeld, M. \& Persons, D. (1996) Multicentric renal angiomyolipoma associated with pulmonary lymphangioleiomyomatosis: case report, with histologic, immunohistochemical, and DNA content analyses. Urology, 48, 476-480.

Taylor, J.R., Ryu, J., Colby, T.V. \& Raffin, T.A. (1990) Lymphangioleiomyomatosis. Clinical course in 32 patients. N. Engl. J. Med., 323, 1254-1260.

The European Chromosome 16 Tuberous Sclerosis Consortium (1993) Identification and charcterization of the tuberous sclerosis gene on chromosome 16. Cell, 75, 1305-1315.

Urban, T., Kuttenn, F., Gomple, A., Marsac, J. \& Lacronique, J. (1992) Pulmonary lymphangiomyomatosis follow-up and long-term outcome with antiestrogen therapy, A report of eight cases. Chest, 102, 472-476.

van Slegtenhorst, M., de Hoogt, R., Hermans, C., Nellist, M., Janssen, B., Verhoef, S., Lindhout, D. \& van den Ouweland, A. (1997) Identification of the tuberous sclerosis gene TSC1 on chromosome 9q34. Science, 277, 805 -808 . 
Wockel, W., Meister, P., Karg, O. \& Morresi-Hauf, A. (1997) Native pulmonary muscular proliferation. Pathol. Res. Pract., 193, 599-605.

Yamashita, Y., Ono, J., Okada, S., Wataya-Kaneda, M., Yoshikawa, K., Nishizawa, M., Hirayama, Y., Kobayashi, E., Seyama, K. \& Hino, O. (2000) Analysis of all exons of TSC1 and TSC2 genes for germline mutations in
Japanese patients with tuberous sclerosis: report of 10 mutations. Am. J. Med. Genet., 90, 123-126.

Yano, S. (2002) Exacerbation of pulmonary lymphangioleiomyomatosis by exogenous oestrogen used for infertility treatment. Thorax, 57, 1085-1086. 